\title{
Power distribution in multi-motor (AWD) powertrain of electric vehicle
}

\author{
Artur Kopczyński ${ }^{1,{ }^{*}}$, and Paweł Roszczyk ${ }^{1}$ \\ ${ }^{1}$ Warsaw University of Technology, Department of Multisource Propulsion Systems, ul. Narbutta 84, \\ 02-524 Warsaw, Poland
}

\begin{abstract}
This article presents the results of analysis of power distribution in an electric vehicle independent all-wheel drive. The utilized method of velocity distribution takes into account the change in the motion resistance occurring on particular wheel. Moreover, the method of determining the change of vertical loads on traction wheels is also described. Theoretical considerations were verified on a dedicated laboratory stand that allows to perform real time simulation for analysed powertrain structure. The results of two different scenarios of vehicle driving in curvilinear motion are presented.
\end{abstract}

\section{Introduction}

In the last decade, a significant increase in the popularity of electric road vehicles has been observed. Therefore, the intensification of scientific research devoted to this subject is an indispensable process. Most of these studies raise issues related to energy analysis of the propulsion system $[1,2]$, component modelling $[3,4]$ and the possibility to reduce energy consumption $[5,6]$. While other studies consider ecological aspects and the impact of transport on the environment $[7,8]$. The variety of power trains structures and the increasing safety requirements pose new problems for designers and researchers. In this paper, the aspects of motion kinematics of a four-wheeled electric vehicle equipped with independent drive of all wheels will be elaborated. These considerations constitute a continuation and extension of the studies presented in [9-11]. In contrast to results described in [12-15], the loss of vehicle stability will not be scrutinised but the power distribution between vehicle wheels will be analysed depending on the parameters set by the driver, in order to meet the kinematic conditions and avoid possible disturbances in the movement trajectory.

\section{Electric vehicle independent All-Wheel Drive (AWD)}

According to the scheme presented in Figure 1, the vehicle is driven by an electric motors (EM) controlled by a motor controllers (MC) and powered by an electrochemical battery (Bat). EM transmit the drive/braking torque to the wheels via drive shafts. A transmission with a fixed ratio can be mounted between the motors and the traction wheels. The prototype vehicle Fiat Phylla and the commercially available Mercedes SLS AMG Electric Drive are

* Corresponding author: artur.kopczynski@pw.edu.pl 
examples of such construction. EM can also be mounted directly in the wheel hubs which save space inside a car. This solution allows for the bus floor lowering and was utilized in the buses of the Chinese company BYD. However, in typical passenger cars the dynamics of movement is definitely bigger. The hub motors cause an unsprang mass increase, which significantly reduces the stability of vehicle movement and performance.

The Central Control Unit (CCU) which is responsible for the proper functioning of the propulsion system, determines the mode and parameters of individual EM on the basis of parameters set by the driver (steering angle, acceleration pedal position and brake pedal position). In Figure 1 the mechanical and electrical connections are presented with continuous (- - and dashed (-- ) lines, respectively. While the arrows indicate the possible direction of the energy flow depending on the EM operating mode (acceleration/braking).

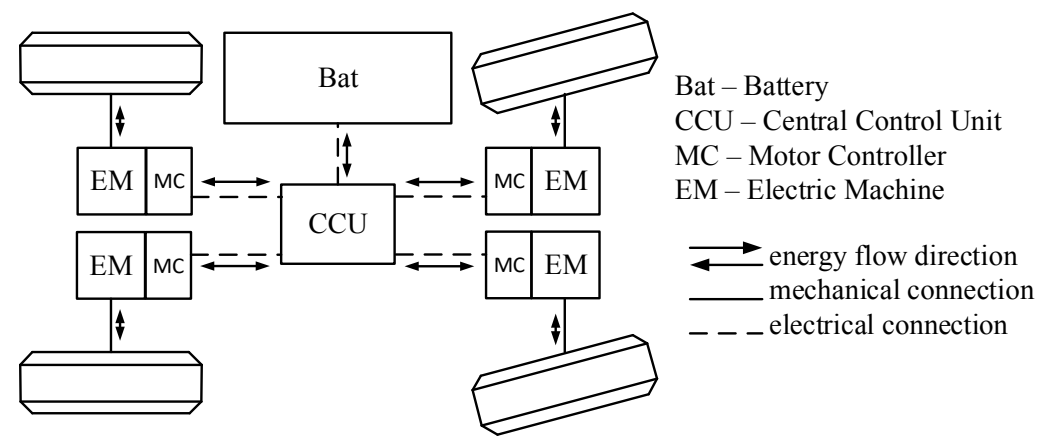

Fig. 1. Power train configuration of electric vehicle multi-motor independent AWD.

\section{Modelling}

In a curvilinear motion, each wheel of a four-wheeled vehicle moves on a different trajectory, which means that each wheel has a different speed. As shown in Figure 2, the speed of each wheel depends on the longitudinal velocity of the centre of gravity (COG) of the vehicle and steering wheel angle (set by the driver) as well as on the geometric parameters of the vehicle (front and rear wheels track $-\mathrm{d}_{\mathrm{f}}, \mathrm{d}_{\mathrm{r}}$, wheelbase $-\mathrm{L}$ ). In the conventional cars, a differential mechanism with two degrees of freedom is responsible for the difference in speeds compensation. In an independent drive this speed compensation must be carried out by controlling the operation of particular EM.

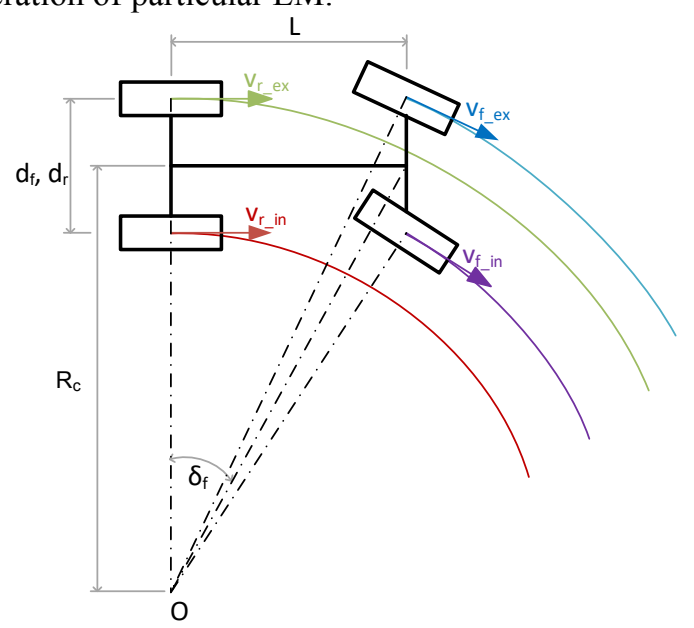

Fig. 2. Kinematics of four-wheeled vehicle during cornering. 
Equations allowing to determine the wheel speed of a four-wheeled vehicle with the Ackerman steering mechanism of front wheels are described and derived in the literature [e.g. 9, 16] and are also presented below.

The angular speed of the front external wheel $\omega_{f_{-} e x}$ is described by the equation:

$$
\omega_{f_{-} e x}(t)=\left[v_{x}(t) / r_{d}\right]\left\{1+\tan \left(\delta_{f}\right) d_{f} / L+\tan ^{2}\left(\delta_{f}\right)\left[1+d_{f}^{2} / L^{2}\right]\right\}^{1 / 2}
$$

The following equation was obtained for the front internal wheel $\omega_{f_{-} i n}$ :

$$
\omega_{f_{-} \text {in }}(t)=\left[v_{x}(t) / r_{d}\right]\left\{1-\tan \left(\delta_{f}\right) d_{f} / L+\tan ^{2}\left(\delta_{f}\right)\left[1+d_{f}^{2} / L^{2}\right]\right\} 1 / 2
$$

The angular speed of the rear external wheel $\omega_{r_{-} e x}$ is described by the equation:

$$
\omega_{r_{-} e x}(t)=\left[v_{x}(t) / r_{d}\right]\left\{1+\left[d_{r} / 2 L\right] \tan \left(\delta_{f}\right)\right\}
$$

And the internal wheel of the rear axis $\omega_{r_{-} \text {in }}$ using the equation:

$$
\omega_{r_{-} \text {in }}(t)=\left[v_{x}(t) / r_{d}\right]\left\{1-\left[d_{r} / 2 L\right] \tan \left(\delta_{f}\right)\right\}
$$

where $v_{x}$ means vehicle longitudinal speed, $\delta_{f}$ - steering angle of virtual wheel located in the middle of front axis, $r_{d}$ - tyre dynamic radius, $d_{f}, d_{r}$ - front and rear wheel track, $L$ - wheelbase.

\subsection{Forces acting on vehicle's wheels}

The vehicle moving on a flat surface is mainly influenced by the forces of aerodynamic drag and rolling resistance. If there is also a change of vehicle speed (e.g. acceleration), the inertia resistance force is also present. Curvilinear movement is additionally influenced by the resistance of the cornering. The rolling $F_{R}$ and cornering $F_{C}$ resistance, presented by Equations (5) and (6), are directly associated with traction wheels [16].

$$
F_{R}=F_{z} f_{t}
$$

The rolling resistance depends on the type of tyre and the surface on which the vehicle moves. This is determined by rolling resistance coefficient $f_{t}=f_{0}+v_{x}(t)^{2} 10^{-5}[-$ ], where $f_{0}$ depends on tyre properties and type of surface .

$$
F_{C}=F_{z}\left[v_{x}(t)^{2} / R_{c} g\right]\left\{\left[l_{r} / L\right] \sin \left(\theta_{f}\right)+\left[l_{f} / L\right] \sin \left(\theta_{r}\right)\right\}
$$

The cornering resistance depends on many factors and is described by more complicated mathematical equation. Lateral deformability of the tyre, defined by the side sleep angles (for front wheels $\theta_{f}$ and for rear wheels $\theta_{r}$ ), is the main reason of occurrence of the cornering resistance. Moreover, the cornering resistance depends on relation of centrifugal acceleration $\left(v_{x}(t)^{2} / R_{c}\right.$, where $R_{c}$ means cornering radius), to acceleration due to gravity $g$. In addition, the value of cornering resistance depends on the location of the centre of gravity (COG), as specified: $l_{f}, l_{r}-$ front and rear axis to COG, and $L$ means wheelbase $\left(L=l_{f}+l_{r}\right)$. Units of all variables are compatible with the SI system.

Both resistance forces depend on the vertical load $F_{z i}$ on the given wheel. Due to this fact in the next chapter a universal method of determination of the instantaneous load on particular wheels of the vehicle will be presented. 


\subsection{Wheel vertical load: pitch and roll}

The method of determination of vertical load caused by pitch (during accelerating or braking) was presented in the work [10]. Forces of vertical load of a given axis during vehicle accelerating are expressed by Equations (7) and (8), where $a$ means vehicle acceleration or deceleration and $h$-height of COG from ground.

$$
\begin{aligned}
& F_{z f}=\left\{m\left[g l_{r}-a h\right]\right\} / L \\
& F_{z r}=\left\{m\left[g l_{f}+a h\right]\right\} / L
\end{aligned}
$$

In case of vehicle braking the forces $F_{z f}$ and $F_{z r}$ are defined by similar Equations to $(7,8)$ but the signs in numerators are opposite.

Determination of the load on each of the wheels caused by roll (during vehicle cornering) is troublesome because a change in the vertical load depends on many factors and constitutes the individual feature of the particular car and its suspension. Whereas the simplified universal model presented below, takes into account the following assumptions that will not significantly affect the results:

- The considered system is an isolated system on which no external forces act;

- Coefficient of tyre adhesion is constant in time and it is the same for all of the wheels;

- There are no slippages.

Another important assumption can be formulated as follows:

- Internal wheels of the vehicle during cornering are unloaded by the same value by which the external wheels are loaded.

This assumption can be described as follows:

$$
m g=F_{z_{-} i n}+F_{z_{-} e x}
$$

For further considerations, please refer to Figure 3.

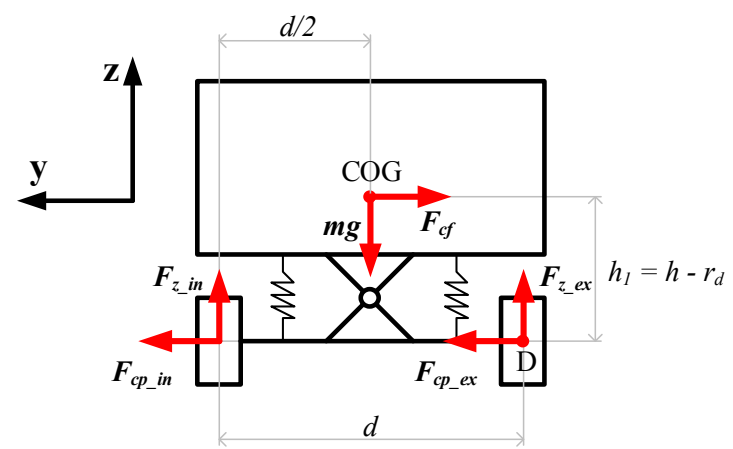

Fig. 3. Forces acting on a vehicle during cornering.

The centrifugal force $F_{c f}$ of such a setting equals to:

$$
F_{c f}=m v_{x}^{2} / R_{c}
$$

The sum of moments in terms of point D:

$$
\begin{gathered}
\Sigma M_{D}=0 \\
F_{c f} h_{1}+F_{z_{-} i n}-m g d / 2=0
\end{gathered}
$$


From $(10,11)$ the following is obtained:

$$
F_{z_{-} \text {in }}=m\left[g / 2-v_{x}^{2} h_{1} / R_{c} d\right]
$$

The sum of forces acting on the vehicle vertically (along with axis $\mathrm{z}$ ):

$$
\begin{gathered}
\Sigma F_{z}=0 \\
F_{z_{-} e x}=m g-F_{z_{-} i n}=m\left[g / 2+v_{x}{ }^{2} h_{l} / R_{c} d\right]
\end{gathered}
$$

\section{Study}

In order to analyse the control of a multi-motor drive, a special laboratory stand was prepared. The block diagram of the stand is presented in Figure 4. The main components are two sets consisting of two electric machines (EM-1 with EM-3 and EM-2 with EM-4) with rotor shafts connected with each other. The inertia discs $\mathrm{J}_{1}$ and $\mathrm{J}_{2}$ are located on shafts that connect the motors. In this set EM-1 works as a drive motor, and EM-3 simulates the motion resistance (generator mode). The situation for the second set of machines looks the same: EM-2 acts as a driving motor and EM-4 as load. Each motor is connected to its controller MC-i equipped with current and voltage probes. Two encoders (E) are used for measuring the rotational speed, one for each set. Power for motors is provided by lead-acid electrochemical batteries that also accumulate energy from EMs operating in generator mode. The verification of the operation of the drive of one axle (front or rear) is possible during one test. The tested sets represent the right and left wheels.

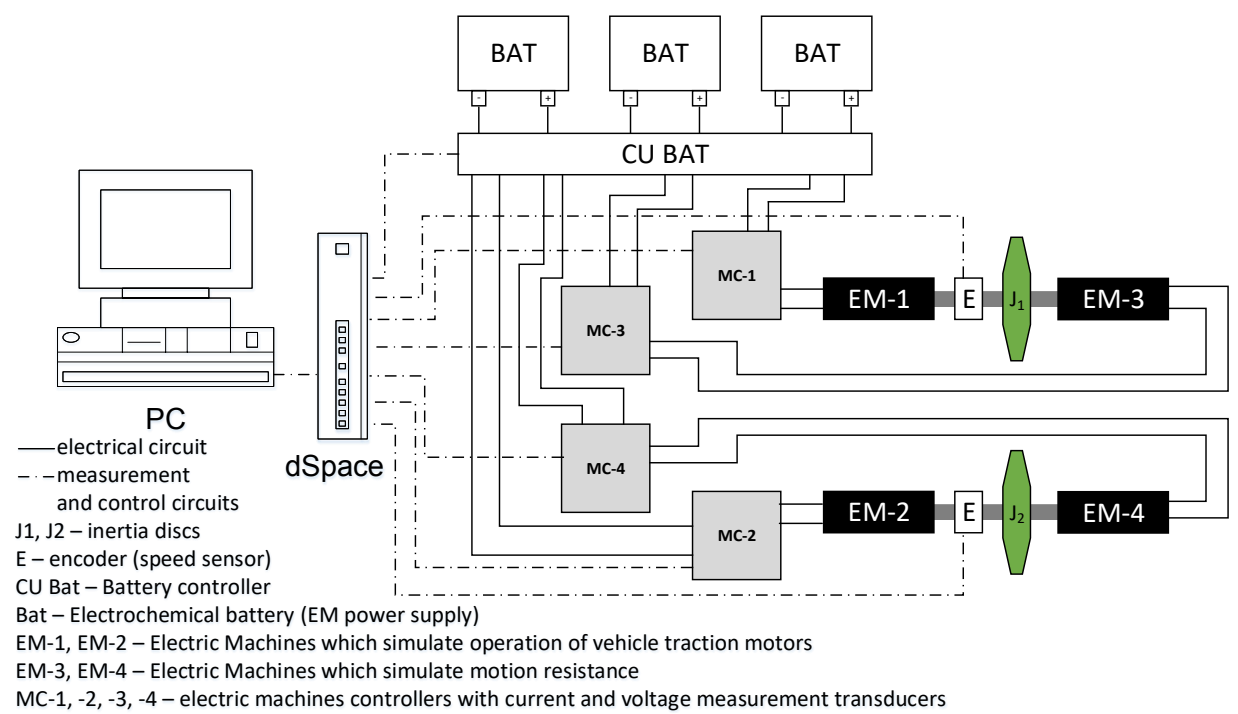

Fig. 4. Bloc diagram of laboratory stand.

The system is managed by rapid control prototyping hardware with dSpace software which allows to perform real time simulation. On the basis of the equations from Chapter 3 , a model was developed in the Matlab Simulink environment, to which the elements responsible for cooperation with the real object (controllers, sensors) were attached. The model developed in Simulink has been automatically converted to the dSpace environment. The instantaneous parameters determined from the simulation model i.e. speeds for drive motors (EM-1 and EM 2) and load current for motors (EM-3 and EM-4), were taken as set 
parameters during tests. The determined values have been scaled to the capabilities of the stand. After taking into account own non-linear resistances of the stand, the calculated resistance forces were scaled to the load current values.

The image of the stand and the measuring and control panel prepared in the dSpace software are presented in Figures 5a and 5b, respectively. The panel can be used to select the reference vehicle speed and the reference steering angle. During the test, the waveforms of given and measured parameters are displayed in plots.

It has been defined that each test is carried out in the following procedure: Initially, the system accelerates to the reference speed assuming a straight line movement and after the speed is reached, the steering angle changes to the reference value. Then, when the vehicle is cornering with a constant radius, braking begins. Set values are determined for each instantaneous condition. In this study, two scenarios were verified for a reference speed of $90 \mathrm{~km} / \mathrm{h}$ and a steering angle of $20^{\circ}$ and a speed of $50 \mathrm{~km} / \mathrm{h}$ and a steering angle of $45^{\circ}$. The tests were carried out for the simulation of the operation of the front and rear drive for the same parameters.

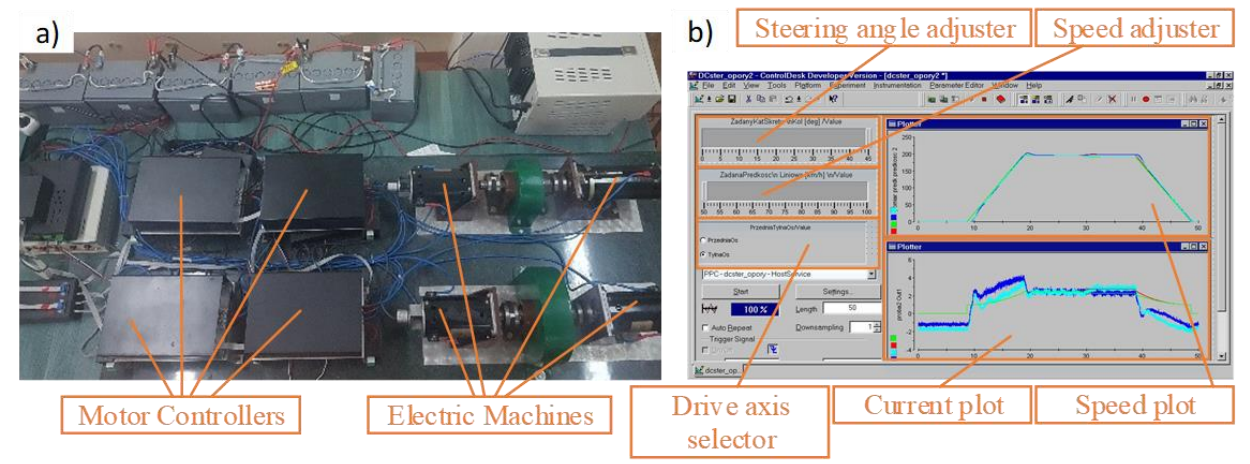

Fig. 5. a) Photo of laboratory stand, b) dSpace control panel.

Table 1 contains the parameters used in the simulation.

Table 1. Input data.

\begin{tabular}{|c|c|c|c|c|c|c|}
\hline $\begin{array}{l}\text { Vehicle } \\
\text { mass }\end{array}$ & $\begin{array}{c}\text { Frontal } \\
\text { area }\end{array}$ & $\begin{array}{l}\text { Aerodynam } \\
\text { ic drag }\end{array}$ & $\begin{array}{c}\text { Rolling } \\
\text { resistance } \\
\text { coefficient }\end{array}$ & $\begin{array}{c}\text { Gear } \\
\text { total ratio }\end{array}$ & $\begin{array}{l}\text { Steering } \\
\text { column } \\
\text { ratio }\end{array}$ & $\begin{array}{c}\text { Centre of } \\
\text { gravity } \\
\text { height }\end{array}$ \\
\hline $\mathrm{m}=600 \mathrm{~kg}$ & $\mathrm{~A}=1.3 \mathrm{~m}^{2}$ & $C_{d}=0.45[-]$ & $\mathrm{f}_{0}=0.01[-]$ & $\mathrm{i}_{\mathrm{c}}=4$ & $\mathrm{i}_{\mathrm{SC}}=15.7$ & $\begin{array}{c}\mathrm{h}=0.45 \\
\mathrm{~m}\end{array}$ \\
\hline Wheelbase & $\begin{array}{l}\text { Front axis to } \\
\text { COG }\end{array}$ & $\begin{array}{l}\text { Rear axis to } \\
\text { COG }\end{array}$ & $\begin{array}{l}\text { Front wheel } \\
\text { track }\end{array}$ & $\begin{array}{c}\text { Rear } \\
\text { wheel } \\
\text { track }\end{array}$ & $\begin{array}{l}\text { Wheel } \\
\text { dynamic } \\
\text { radius }\end{array}$ & $\begin{array}{l}\text { Laborator } \\
\text { y stand } \\
\text { scale }\end{array}$ \\
\hline $\mathrm{L}=2.3 \mathrm{~m}$ & $\mathrm{l}_{\mathrm{f}}=1.3 \mathrm{~m}$ & $l_{\mathrm{r}}=1 \mathrm{~m}$ & $\mathrm{df}=1.42 \mathrm{~m}$ & $\mathrm{dr}=1.4 \mathrm{~m}$ & $\begin{array}{c}\mathrm{r}_{\mathrm{d}}=0.285 \\
\mathrm{~m}\end{array}$ & $1: 100$ \\
\hline
\end{tabular}

\subsection{Real-time simulation results}

The results for the tests are shown in Figures 6 and 7. A comparison of the set and measured signal is included in each plot. In order to show better the waveform in time when the steering angle changes only the relevant part of each plot has been presented. The acceleration and braking phases have been omitted because they are not relevant to the considerations undertaken in this work.

In the case of speed waveforms, it is visible that the measured signals follow the set values. When there is a change in speed, the differences appear in dynamic states, which is 
related to the mechanical inertia of the elements. A good correlation of the results was also obtained for the current waveforms. However, in this case the calculated load (from the motion resistance) is compared to the actual current waveform of the drive motors. By this, the correct operation of the stand, which satisfactorily reflects the tested powertrain system together with the application of instantaneous motion resistance on particular wheels, has been confirmed. A better reflection of the given speeds was obtained for the test carried out at a speed of $50 \mathrm{~km} / \mathrm{h}$, however, worse was obtained in the case of currents. The improvement in reaching the set parameter can be obtained by improving the settings of the regulators. Unfortunately, the tested object is nonlinear and it is impossible to select these settings of regulators based on the classical theory, simultaneously ensuring correct operation in the full range of speeds for both analysed parameters (speed and current).
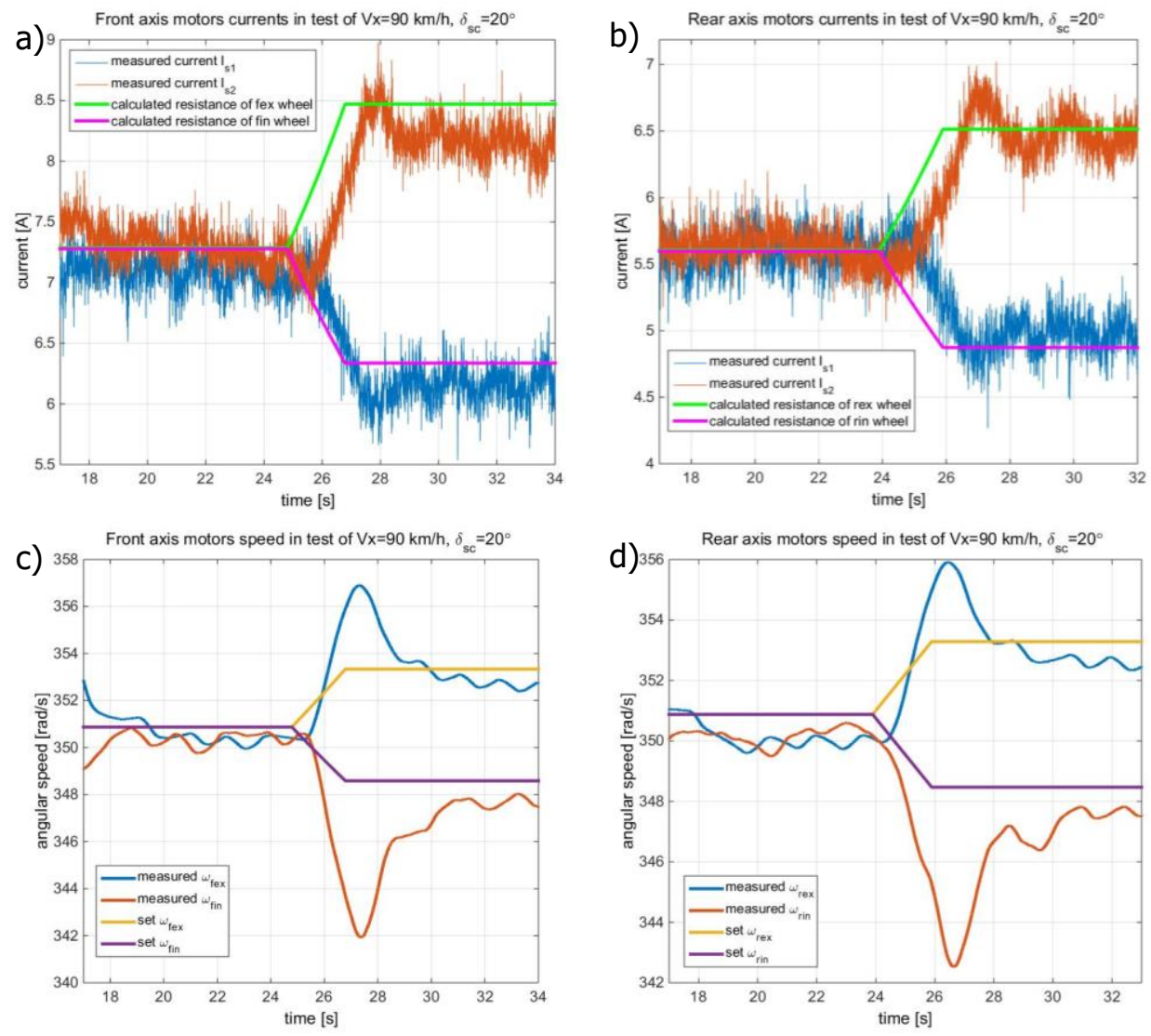

Fig. 6. Results of real time simulation of the test of vehicle speed equal to $90 \mathrm{~km} / \mathrm{h}$ and steering angle $\delta_{S C}$ equal to $20^{\circ}$ a) front axis currents, b) rear axis currents, c) front axis wheels angular speeds, d) rear axle wheel angular speeds. 

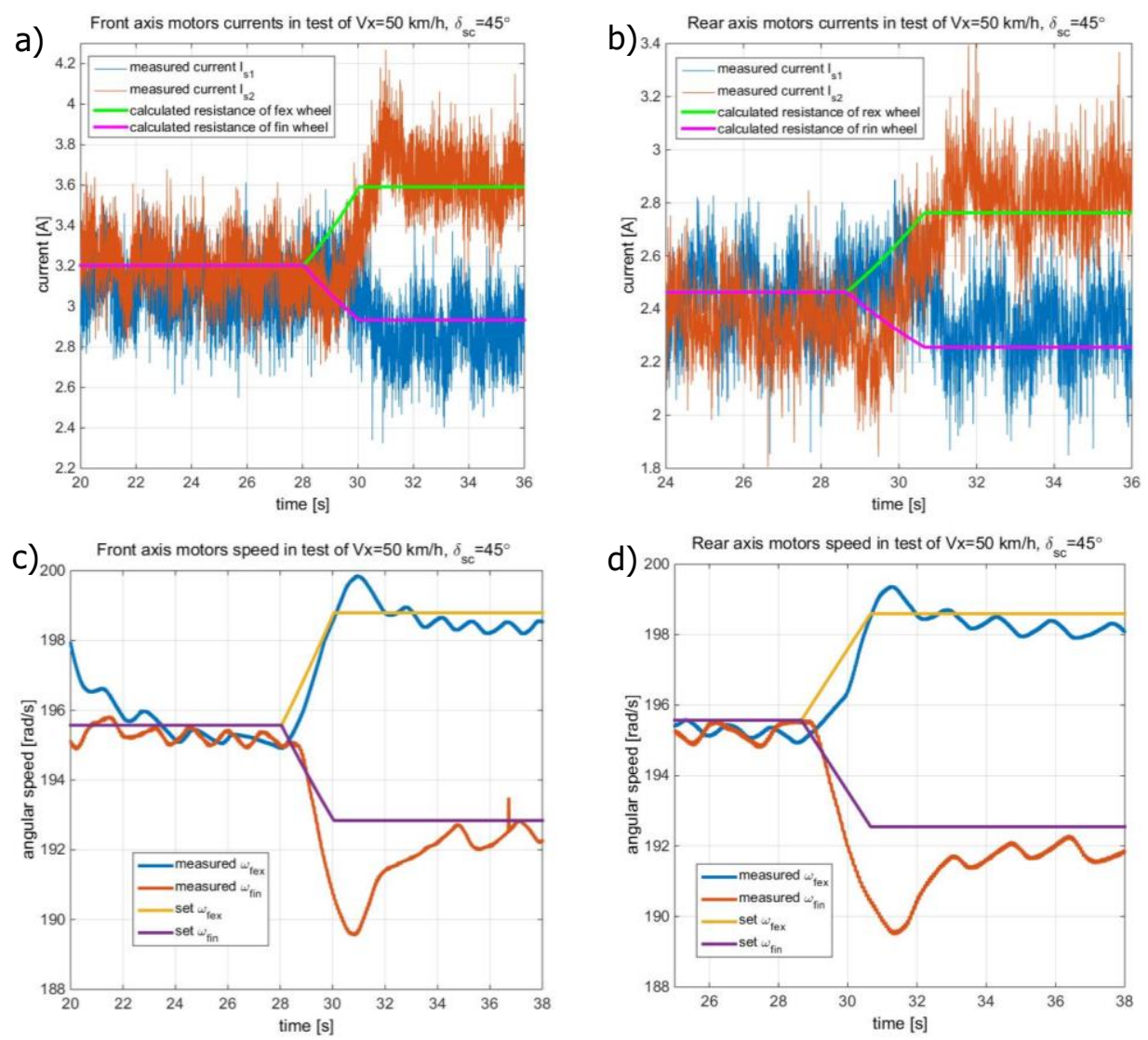

Fig. 7. Results of real time simulation of the test of vehicle speed equal to $50 \mathrm{~km} / \mathrm{h}$ and steering angle $\delta_{S C}$ equal to $45^{\circ}$ a) front axis currents, b) rear axis currents, c) front axis wheels angular speeds, d) rear axle wheel angular speeds.

The current percentage error for the worst case (test front drive $90 \mathrm{~km} / \mathrm{h}$ ) is presented in Figure $8 \mathrm{a}$ while the speed error (for the worst case test - rear drive with the speed of $50 \mathrm{~km} / \mathrm{h}$ ) in Figure $8 \mathrm{~b}$. The speed error is below $2 \%$ which is satisfactory, while the mean value of the current error amounts to approx. $10 \%$ (excluding the peaks). Given the small values of the measured current and the possible accuracy of the measurement and the relatively large own stand resistances, this error should also be considered as acceptable. 
a)

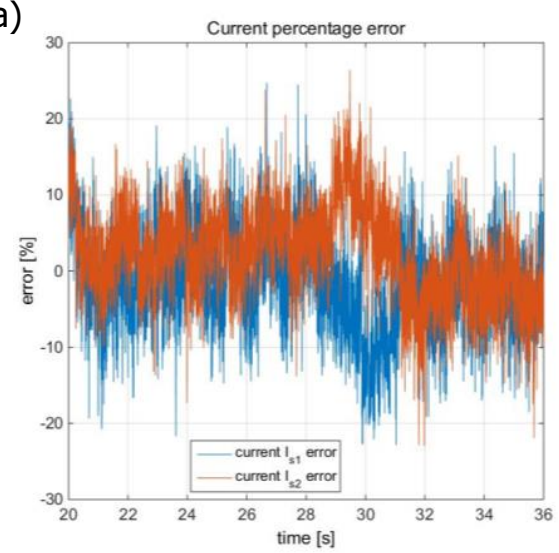

b)

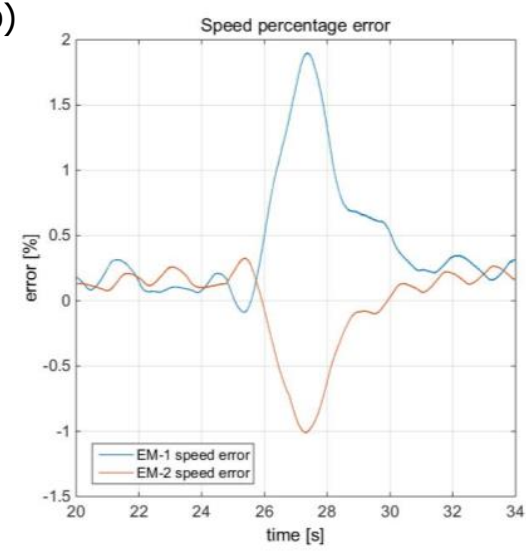

Fig. 8. a) example of current percentage error, b) example of speed percentage error.

\section{Conclusion}

The article presents the method of speed distribution for electric vehicle independent all-wheel drive. The change in motion resistance on each wheel was taken into account depending on the instantaneous values of the parameters determining the change in vertical loads on each wheel. The simplifications used in the determination of vertical loads have been made intentionally to create a more versatile model. However, it is expected that these simplifications will not significantly affect the obtained results. For the verification of theoretical considerations, tests were carried out on a laboratory stand which reflects the work of the analysed propulsion system. The correctness of the operation of the laboratory stand and thus of the analysed method of multi-motor drive control was demonstrated. A drawback constitutes the high value of the stand's own resistance, which also hampered the adjustment of the settings of the regulators, which translated into the accuracy of the results. Nevertheless, the accuracy is sufficient to draw valuable conclusions. Even though in a real environment there is a number of other factors that have been omitted in these considerations such as the occurrence of tyre slip, road gradient, weather condition, etc., the presented research results take into account these that have a main, fundamental impact.

\section{References}

1. Z. Chłopek, J. Lasocki, P. Wójcik, A. J. Badyda, Int. J. Green Energy 15, 773-779 (2018)

2. A. Kopczyński, Z. Liu, P. Krawczyk, E3S Web of Conferences 44, 00074 (2018)

3. E. Jankowska, K. Kopciuch, M. Błażejczak, W. Majchrzycki, P. Piórkowski, A. Chmielewski, K.J. Bogdziński, Advances in Automation, Robotics and Measurement Techniques 743, 339-349 (2018)

4. A. Hajduga, Proceedings of $23^{\text {rd }}$ International Conference on Methods \& Models in Automation \& Robotics (MMAR), 843-848 (2018)

5. A. Hajduga, Proceedings of $23^{\text {rd }}$ International Conference on Methods \& Models in Automation \& Robotics (MMAR), 622-627 (2018)

6. A. Kopczyński, P. Piórkowski, P. Roszczyk, IOP Conf. Ser. Mater. Sci. Eng. 421, 022016 (2018) 
7. Z. Chłopek, J. Biedrzycki, J. Lasocki, P. Wójcik, Eksploatacja i Niezawodnosc Maintenance and Reliability 17, 35-41 (2015)

8. A. Kopczyński, P. Krawczyk, J. Lasocki, E3S Web of Conferences 44, 00073 (2018)

9. A. Szumanowski, Ed., Designing of electronic differentials of electric road vehicles (WN ITeE-PIB, Radom, 2007)

10. A. Kopczyński, Logistyka: czasopismo dla profesjonalistów 3, 2269 (2015)

11. A. Kopczyński, P. Krawczyk, Proceedings of the Institute of Vehicles 112, 49 (2017)

12. W. Cao, Z. Liu, Y. Chang, A. Szumanowski, Math. Probl. Eng. 2017, 5170492 (2017)

13. W. Cao, H. Liu, Y. Chang, Z. Liu, A. Szumanowski, Energies 10, 1641 (2017)

14. W. Liu, H. He, J. Peng, Math. Probl. Eng. 2013, 408965 (2013)

15. H. He, J. Peng, R. Xiong, H. Fan, Energies 7, 3748-3763 (2014)

16. D. Schramm, M. Hiller. Vehicle Dynamics Modeling and Simulation (Springer, 2014)

17. A. Szumanowski, Y. Chang, Z. Liu, P. Krawczyk, Int. J. Vehicle Des. 76, 1-19 (2018) 